\title{
A Pathological Profile of Oesophageal Carcinoma
}

\author{
Dr. Shreesha Khandige, Suchithra A. Shetty ${ }^{*}$ \\ Professor and HOD, Department of Pathology, Kanachur Institute of Medical Sciences, Mangalore
}

DOI: $10.36348 /$ sjpm.2020.v05i02.007 | Received: 03.02.2020 | Accepted: 10.02 .2020 | Published: 16.02 .2020

*Corresponding author: Suchithra A Shetty

Abstract

Oesophageal carcinoma ranks one of the commonest of all cancers. It sure finds a spot in the top ten. It also ranks itself in the top 5 when mortality of the patient is concerned. ${ }^{1}$ Oesophageal Cancers are more often encountered than when compared to statistics of any other era and we encounter it more often in the clinics. The frequency has been on a positive inclination if not straight. It is one of the serious malignancies and has one of the worst prognoses. The morbidity and the mortality is also on a higher scale. The trends are expected to increase in the next decade or two as more and more urbanisation and industrialisation are happening thus indirectly leading to life style modifications. Obesity is also one of the more important causes or rather says obesity has been linked directly to the oesophageal cancers. With increase in the incidence and prevalence of the obesity and also the unhealthy life style modifications, more number of cases is expected to encounter. If global scenario is considered then higher incidence is reported in the developing nations and also majority of the studies indicate that squamous cell carcinoma is the commonest variety. In the last half century more number of cases has been reported than in any other point of time.

Keywords: Oesophageal, Carcinoma, Lifestyle, Retrospective, Profile.

Copyright @ 2020: This is an open-access article distributed under the terms of the Creative Commons Attribution license which permits unrestricted use, distribution, and reproduction in any medium for non-commercial use (NonCommercial, or CC-BY-NC) provided the original author and sources are credited.

\section{INTRODUCTION}

Oesophageal carcinoma is one of the commonest of all cancers [1]. Oesophageal Cancers are more often encountered than when compared to statistics of any other era and we encounter it more often in the clinics. The frequency has been on a positive inclination if not straight. It is one of the serious malignancies and has one of the worst prognoses. The morbidity and the mortality is also on a higher scale. The trends are expected to increase in the next decade or two as more and more urbanisation and industrialisation are happening thus indirectly leading to life style modifications. Obesity is also one of the more important causes or rather says obesity has been linked directly to the oesophageal cancers. With increase in the incidence and prevalence of the obesity and also the unhealthy life style modifications, more number of cases is expected to encounter. If global scenario is considered then higher incidence is reported in the developing nations and also majority of the studies indicate that squamous cell carcinoma is the commonest variety. In the last half century more number of cases has been reported than in any other point of time. According to a survival analysis study the 5 year survival rate is very poor and statistics from that particular study suggest it be nearing 15 to 20 per cent. That means less than one fourth of the total patients diagnosed with this dreaded disease will live and touch the fifth year mark. And this is after the modern diagnosis and the treatment that has been implemented for the patients. The scenario is much worst if the treatment is not taken [2]. One more study indicated that the survival rate is less than 15 percent in the developed countries [3]. In India, Karnataka, Tamil Nadu, Kerala and Assam are the commonest places where it has been encountered very frequently [4]. Since the prognosis in oesophageal carcinoma is extremely poor and as there seems to be little prospect for early detection or treatment, a better understanding of the aetiology/risk factors may suggest opportunity for its primary prevention [5]. In United states Adenocarcinoma has now become the leading cause of oesophageal cancer $80 \%$ to $90 \%$ of cases[6]. Various factors including tobacco consumption, unhealthy diet and diet deficient in trace elements, alkalinity of soil, genetic aberrations and socioeconomic status have been implicated in the aetiology of Oesophageal acncer [7, 8]. This study, aims to study the pathological profile of patients suffering from this dreaded disease.

\section{AIMS AND OBJECTIVES}

The aim of the study is to build a clinical profile of patients suffering from Oesophageal Cancer. 


\section{MATERIALS AN METHODS}

This study was done in the Department of Medicine, Kanachur Institute of medical Sciences, Mangalore.

This study was done from January 2018 to June 2019

This study was done in 30 confirmed cases.

\section{Inclusion Criteria} carcinoma.

Histological/Pathological -proven oesophageal

\section{Exclusion Criteria}

Secondaries in the oesophagus

\section{RESULTS}

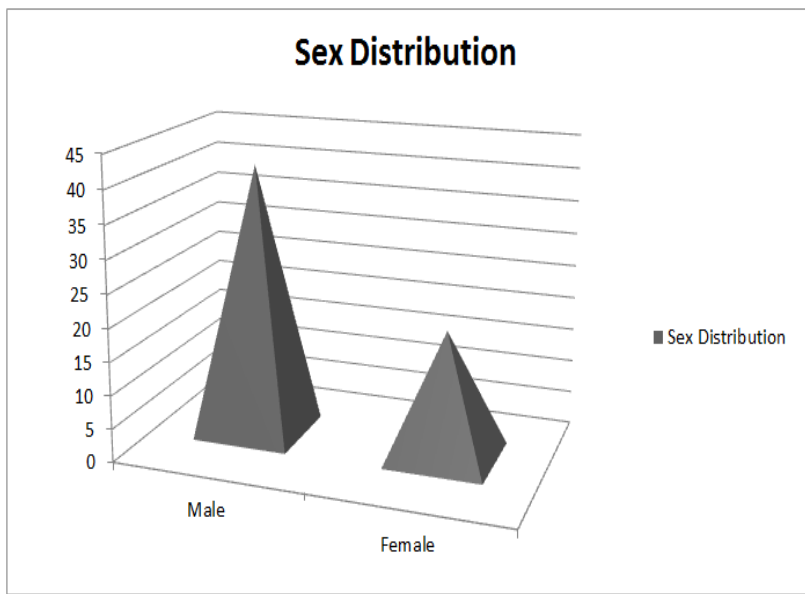

Graph-1: Sex Distribution

Table-1

\begin{tabular}{|l|l|l|}
\hline Sex & Male & Female \\
\hline & $69.57 \pm 12.26$ years & $64.84 \pm 17.68$ years \\
\hline
\end{tabular}

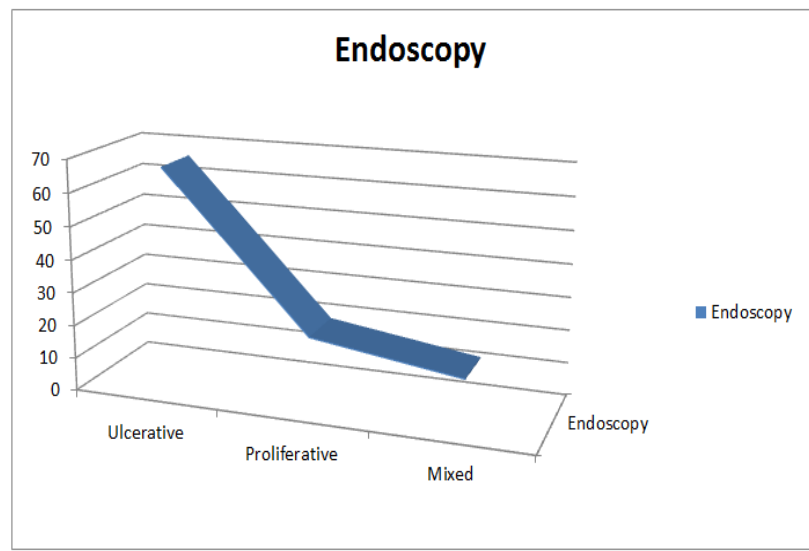

Graph-3: Endoscopic Signs

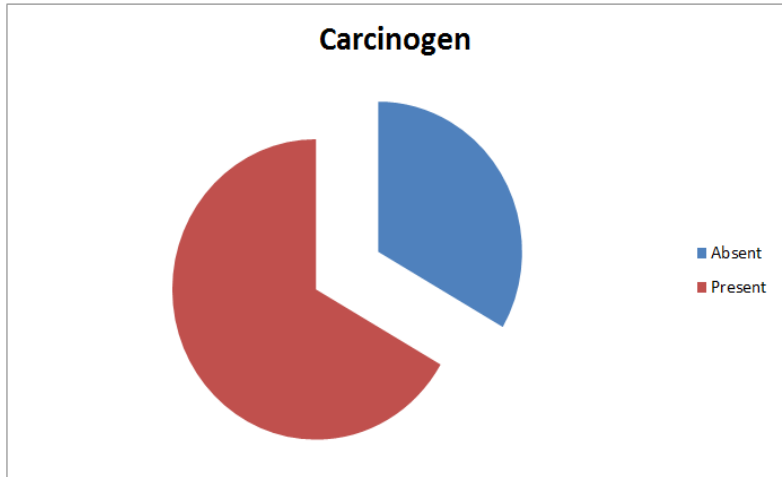

Graph-4: Known Carcinogen Addiction

Table-2

\begin{tabular}{|l|l|}
\hline Habit & Frequency \\
\hline Smoking & 11 \\
\hline Drinking & 21 \\
\hline Betel Nut Chewing & 19 \\
\hline
\end{tabular}

Table-3: Endoscopy Level

\begin{tabular}{|l|l|}
\hline$<20 \mathrm{cms}$ & 01 \\
\hline $20-25 \mathrm{~cm}$ & 02 \\
\hline $25-30 \mathrm{~cm}$ & 05 \\
\hline $30-35 \mathrm{~cm}$ & 21 \\
\hline $35-40 \mathrm{~cm}$ & 01 \\
\hline
\end{tabular}

The most common site was around 30 to 35 cms from the central incisors. This was followed by around 20 to $25 \mathrm{cms}$.

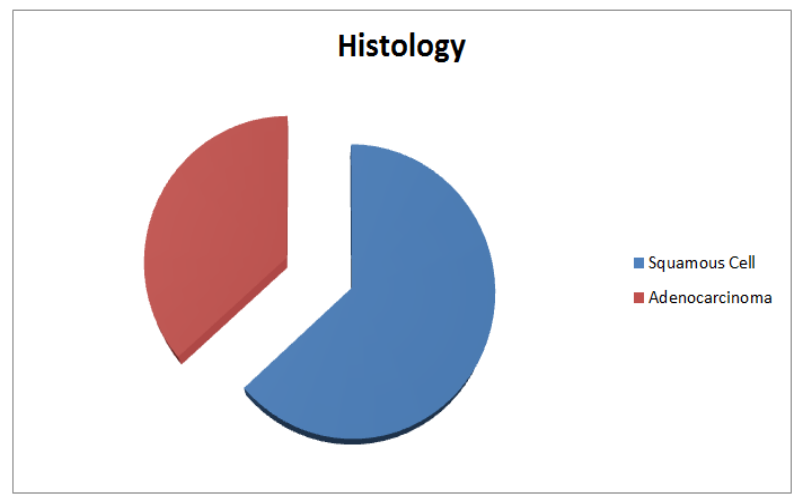

Graph-5: Histology Variety 


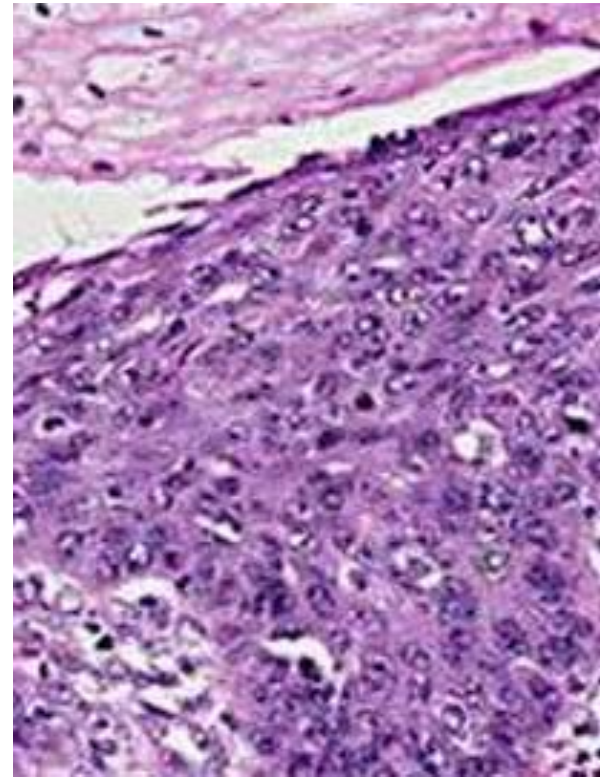

Image-1: Squamous Cell Carcinoma

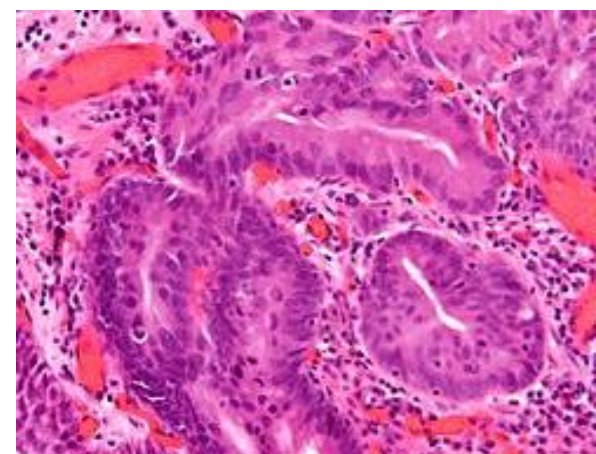

Image-2: Adenocarcnoma

\section{DISCUSSION}

The two main types (i.e. squamous-cell carcinoma and adenocarcinoma) have distinct sets of risk factors Squamous-cell carcinoma is linked to lifestyle factors such as smoking and alcohol. Adenocarcinoma has been linked to effects of long-term acid reflux. Tobacco is a risk factor for both types. Both types are more common in people over 60 years of age.

\section{Squamous-cell carcinoma}

The two major risk factors for esophageal squamous-cell carcinoma are tobacco (smoking or chewing) and alcohol. The combination of tobacco and alcohol has a strong synergistic effect. Some data suggest that about half of all cases are due to tobacco and about one-third to alcohol, while over threequarters of the cases in men are due to the combination of smoking and heavy drinking. Risks associated with alcohol appear to be linked to its aldehyde metabolite and to mutations in certain related enzymes. ${ }^{[16]}$ Such metabolic variants are relatively common in Asia.
Other relevant risk factors include regular consumption of very hot drinks (over $65^{\circ} \mathrm{C}$ or $149^{\circ} \mathrm{F}$ ) and ingestion of caustic substances. High levels of dietary exposure to nitrosamines (chemical compounds found both in tobacco smoke and certain foodstuffs) also appear to be a relevant risk factor. Unfavorable dietary patterns seem to involve exposure to nitrosamines through processed and barbecued meats, pickled vegetables, etc., and a low intake of fresh foods. Other associated factors include nutritional deficiencies, low socioeconomic status, and poor oral hygiene [16]. Chewing betel nut (areca) is an important risk factor in Asia. Physical trauma may increase the risk. This may include the drinking of very hot drinks.

\section{Adenocarcinoma}

Male predominance is particularly strong in this type of esophageal cancer, which occurs about 7 to 10 times more frequently in men. This imbalance may be related to the characteristics and interactions of other known risk factors, including acid reflux and obesity.

The long-term erosive effects of acid reflux (an extremely common condition, also known as gastroesophageal reflux disease or GERD) have been strongly linked to this type of cancer. Longstanding GERD can induce a change of cell type in the lower portion of the esophagus in response to erosion of its squamous lining. This phenomenon, known as Barrett's esophagus, seems to appear about 20 years later in women than in men, possibly due to hormonal factors. ${ }^{[}$Having symptomatic GERD or bile reflux makes Barrett's esophagus more likely, which in turn raises the risk of further changes that can ultimately lead to adenocarcinoma. The risk of developing adenocarcinoma in the presence of Barrett's esophagus is unclear, and may in the past have been overestimated.

Being obese or overweight both appear to be associated with increased risk. The association with obesity seems to be the strongest of any type of obesityrelated cancer, though the reasons for this remain unclear. Abdominal obesity seems to be of particular relevance, given the closeness of its association with this type of cancer, as well as with both GERD and Barrett's esophagus. This type of obesity is characteristic of men. Physiologically, it stimulates GERD and also has other chronic inflammatory effects.

Helicobacter pylori infection (a common occurrence thought to have affected over half of the world's population) is not a risk factor for esophageal adenocarcinoma and actually appears to be protective. Despite being a cause of GERD and a risk factor for gastric cancer, the infection seems to be associated with a reduced risk of esophageal adenocarcinoma of as much as $50 \%$. The biological explanation for a protective effect is somewhat unclear. One explanation 
is that some strains of $H$. pylori reduce stomach acid, thereby reducing damage by GERD. Decreasing rates of $H$. pylori infection in Western populations over recent decades, which have been linked to better hygiene and increased refrigeration of food, could be a factor in the concurrent increase in esophageal adenocarcinoma.

Female hormones may also have a protective effect, as EAC is not only much less common in women but develops later in life, by an average of 20 years. Although studies of many reproductive factors have not produced a clear picture, risk seems to decline for the mother in line with prolonged periods of breastfeeding.

Tobacco smoking increases risk, but the effect in esophageal adenocarcinoma is slight compared to that in squamous cell carcinoma, and alcohol has not been demonstrated to be a cause. Our study stands in agreement with the other study conducted by Premaletha Narayanan et al. [9].

\section{CONCLUSION}

Pathological profile of patients suffering from Oesophageal Cancer has been successfully built.

\section{REFERENCES}

1. Herszényi, L., Tulassay, Z.(2010). Epidemiology of gastrointestinal and liver tumors. Eur Rev Med Pharmacol Sci, 14(4):249-258.
2. Pennathur, A., Gibson, M.K., Jobe B.A. (2013). Esophageal carcinoma. The Lancet, 381:400-412.

3. Kamangar, F., Malekzadeh, R., Dawsey, S.M. (2007). Esophageal cancer in Northeastern Iran: a review. Arch Iran Med, 10(1):70-82.

4. Chitra, S., Ashok, L., Anand, L. (2004). Risk factors for esophageal cancer in Coimbatore, southern India: a hospital-based case-control study. Indian J Gastroenterol, 23(1):19-21.

5. Park, K. (2011). Park's Textbook of preventive and social medicine. 21st edn. Jabalpur: Banarasidas Bhanot Publishers, 10-12.

6. Absi, A., Adelstein, D.J., Rice, T. (2013). esophageal cancer.

http://www.clevelandclinicmededcom/medicalpubs /di seasemanagement/hematology-

oncology/esophagealcancer/

7. Cheng, K.K.(1994). The etiology of esophageal cancer in Chinese. Semin Oncol, 21(4):411-415.

8. Mahboubi, E., Kmet, J., Cook, P.J. (1973). Esophageal cancer studies in the Caspian Littoral of Iran: the Caspian cancer registry. Br J Cancer, 28(3):197-214.

9. Narayanan, P., Ashraf, A.A.S., Philip, A. (2017). Oesophageal carcinoma profile- A retrospective study. J. Evid. Based Med. Healthc, 4(93), 5642$5645 /$ 